\title{
A CONSTANTE VIOLAÇÃO DOS CONHECIMENTOS TRADICIONAIS ASSOCIADOS À BIODIVERSIDADE E O NOVO CONSTITUCIONALISMO LATINO-AMERICANO COMO CAMINHO A SER TRILHADO PARA A SUA EFETIVA PROTEÇÃO
}

\author{
Nathalie Kuczura Nedel \\ Isabel Christine De Gregori**
}

RESUMO: O desrespeito aos conhecimentos tradicionais associados à biodiversidade é latente, mesmo havendo previsão para a sua proteção. Assim, cabe perquirir em que medida o novo constitucionalismo latino-americano pode ser considerado como um caminho apto a efetivar proteção de referidos conhecimentos? Para tanto, utilizar-se-á o método de abordagem dedutivo e como método de procedimento o estruturalista. Ademais, dividir-se-á o artigo em duas seções. Na primeira, analisar-se-á os conhecimentos tradicionais e a ineficácia dos mecanismos protetivos e, na segunda, a possibilidade de adoção do novo constitucionalismo latino-americano como sendo uma forma de proteção desses conhecimentos.

Palavras-chave: Conhecimentos tradicionais associados à biodiversidade; ineficácia; novo constitucionalismo latino-americano; proteção.

\section{THE CONSTANT VIOLATION OF TRADITIONAL KNOWLEDGE ASSOCIATED WITH BIODIVERSITY AND THE NEW LATIN AMERICAN CONSTITUTIONALISM AS A WAY TO BE TRILATED FOR ITS EFFECTIVE PROTECTION}

ABSTRACT: The lack of respect for traditional knowledge associated with biodiversity is latent, even if there is provision for its protection. It is necessary to investigate to what extent the Latin American constitutionalism can be considered as a suitable way to protection of said knowledge? Was employed the method of deductive approach and method of procedure or structuralist. The article will be divided into two sections. In the first, we will analyze the traditional knowledge and the inefficacy of the protective mechanisms and, secondly, the possibility of adopting the Latin American constitutionalism as a way of protecting this knowledge.

Keywords: Traditional knowledge associated with biodiversity; inefficiency; Latin American constitutionalism; protection

\section{CONSIDERAÇÕES INICIAIS}

\footnotetext{
* Doutoranda em Direito pela Universidade do Rio dos Sinos (UNISINOS). Professora e Coordenadora de Pesquisa, Monografia e Extensão da Faculdade de Direito de Santa Maria (FADISMA). Mestre em Direito pelo Programa de Pós-graduação em Direito da Universidade Federal de Santa Maria (UFSM). Pesquisadora do Grupo de Pesquisa em Propriedade Intelectual na Contemporaneidade. Graduada em Direito pela UFSM. E-mail: nkuczura@gmail.com.

** Professora Adjunta do Departamento de Direito da Universidade Federal de Santa Maria (UFSM). Doutora em Desenvolvimento Regional pela Universidade de Santa Cruz do Sul (UNISC). Mestre em Integração LatinoAmericana pela Universidade Federal de Santa Maria (UFSM). Graduada em Direito pela Universidade Federal de Santa Maria (UFSM). Coordenadora do Grupo de Pesquisa em Propriedade Intelectual na Contemporaneidade, certificado pela UFSM e registrado no CNPQ E-mail: isabelcsdg@ gmail.com.
}

CONPEDI LAW REVIEW | QUITO - EQUADOR | v. 4 | n. 2 | p. 21 - 36 | JUL - DEZ | 2018 
O constitucionalismo, definido como movimento que agrega diferentes nuances de natureza política, jurídica, cultural e social, tem acarretado, ao longo do tempo, as mais diversas e significativas transformações históricas. Aliado ao adjetivo "latino-americano", o termo "constitucionalismo latino-americano" é uma expressão que vem impregnada de significados, especialmente se considerarmos as últimas décadas vivenciadas no século XX. A acentuada relação entre a temática do constitucionalismo com a perspectiva latino-americana ganha dimensão ainda maior o quando o propósito é o de garantir proteção à biodiversidade. O traço comum e de característica marcante no qual estão envolvidos os países latinoamericanos, considerados como megabiodiversos e que detém uma gama de conhecimentos tradicionais em seu bojo.

Os conhecimentos tradicionais associados à biodiversidade há décadas são pauta de importantes instrumentos internacionais, alguns que visam proteger os interesses dos países do Norte, como é o caso do Acordo sobre os Aspectos dos Direitos de Propriedade Intelectual Relacionados ao Comércio (TRIPS) e outros que tutela os interesses dos Países do Sul, como a Convenção sobre Diversidade Biológica (CDB). Além dessas normativas no âmago internacional, internamente, os países também possuem normas que visam proteger a propriedade privada desses conhecimentos ou a cultura conjugada com o meio ambiente ecologicamente equilibrado, a depender de que país se está tratando. Porém, o certo é que prevalece o interesse dos bioprospectores, sendo a violação aos conhecimentos tradicionais latente e constante.

Nesse contexto, cabe perquirir em que medida o novo constitucionalismo latino americano pode ser considerado como um caminho apto a efetivar proteção de referidos conhecimentos? Sendo assim, objetiva-se verificar a possibilidade de utilização do novo constitucionalismo latino-americano como sendo uma forma de efetivamente proteger os conhecimentos tradicionais associados à biodiversidade, afastando a prevalência do interesse dos países do Norte.

Para responder ao problema de pesquisa proposto e cumprir com o aludido objetivo, utilizar-se-á como método de abordagem o dedutivo, posto que se realizará uma conexão descendente, iniciando-se por percepções amplas sobre os conhecimentos tradicionais e os mecanismos e o que circundam para, por fim, apreciar a possibilidade de o novo constitucionalismo latino-americano, de fato, protege-los. Já como método de procedimento empregar-se-á o estruturalista, pois se parte da análise de um fenômeno concreto, qual seja, a 
A CONSTANTE VIOLAÇÃO DOS CONHECIMENTOS TRADICIONAIS ASSOCIADOS À BIODIVERSIDADE E O NOVO CONSTITUCIONALISMO LATINOAMERICANO COMO CAMINHO A SER TRILHADO PARA A SUA EFETIVA PROTEÇÃO

aplicação das regulamentações jurídicas no tocante aos conhecimentos tradicionais associados, para se elevar a um nível abstrato, a fim de verificar a possibilidade de o novo constitucionalismo latino-americano proteger esses conhecimentos, para, ao final, retornar ao caso concreto, para auferir a viabilidade de aplicação do que foi estruturado abstratamente. Ainda, importante ressaltar que o presente artigo enquadra-se no Grupo de Trabalho 1 - Novo Constitucionalismo Latino-Americano - do IX Encontro Internacional do CONPEDI - Quito Equador.

Ademais, para uma melhor compreensão do tema, dividir-se-á o artigo em duas seções. Na primeira, analisar-se-á os conhecimentos tradicionais e a ineficácia dos mecanismos protetivos e, na segunda, a possibilidade de adoção do novo constitucionalismo latino americano como sendo uma forma de proteção desses conhecimentos.

\section{A INEFICÁCIA DOS MECANISMOS PROTETIVOS DOS CONHECIMENTOS TRADICIONAIS ASSOCIADOS À BIODIVERSIDADE}

Os conhecimentos tradicionais associados são aqueles produzidos pelas chamadas populações tradicionais, as quais se configuram como sendo aquelas comunidades que detém uma estreita relação com o meio ambiente, ocupando-se dos espaços naturais e manejando os recursos neles alocados para a própria subsistência. Em suma, as comunidades tradicionais são grupos humanos diferenciados no que tange ao aspecto cultural, posto que reproduzem historicamente seu modo de vida, de maneira parcialmente isolada, pautando-se na cooperação social e nas relações com a natureza. Tal noção refere-se tanto a povos indígenas quanto a segmentos da população nacional, que desenvolvem modos particulares de existência, adaptados a nichos ecológicos específicos. (DIEGUES, 2001, p. 22)

A Lei 13.123 de 2015, responsável por tratar dos conhecimentos tradicionais, em âmbito interno, conceitua as comunidades tradicionais, nos seguintes termos:

grupo culturalmente diferenciado que se reconhece como tal, possui forma própria de organização social e ocupa e usa territórios e recursos naturais como condição para a sua reprodução cultural, social, religiosa, ancestral e econômica, utilizando conhecimentos, inovações e práticas geradas e transmitidas pela tradição; (BRASIL, 2015)

Ainda, tendo por base a legislação interna, tem-se o Decreto 6.040 de 2007, o qual instituiu a Política Nacional de Desenvolvimento Sustentável e Comunidades Tradicionais e que define estas como sendo grupos culturalmente diferenciados e que de tal forma se reconhecem. Ao lado desse elemento, deve-se observar que essas comunidades possuem 
formas próprias de organização social e que ocupam territórios e recursos naturais como condição para a sua reprodução cultural, social, religiosa, ancestral e econômica, utilizando conhecimentos, inovações e práticas geradas. (BRASIL, 2007)

Evidente, pois que o conceito doutrinário coaduna-se com o conceito legal, demonstrando a correlação existente, no âmbito das comunidades tradicionais, entre cultura e meio ambiente ecologicamente equilibrado, demonstrando-se uma preocupação intergeracional. Frise que ambos se tratam de direitos fundamentais, que possuem previsão constitucional, sendo, portanto, necessário proteger esses direitos.

Essa estreita ligação entre meio ambiente e cultura associado aos modos de vida peculiares faz com que as comunidades tradicionais produzam certos conhecimentos, os quais são conhecidos como conhecimentos tradicionais associados à biodiversidade, os quais se configuram, portanto, como sendo conjuntos complexos de informações intergeracionais, que não se restringe a um simples repertório de ervas medicinais, abarcam, dessa maneira,

desde técnicas de manejo de recursos naturais até métodos de caça e pesa, conhecimentos sobre diversos ecossistemas e sobre propriedade farmacêuticas, alimentícias e agrícolas de espécies as próprias categorizações e classificações de espécies de flora e fauna utilizadas pelas populações tradicionais.( SANTILLI, 2005. p. 192)

Evidente, dessa forma, que esses conhecimentos são coletivos. Ou seja, pertencem àquela determinada comunidade ou, ainda, a diversas comunidades, que por estarem alocadas em regiões similares, por exemplo, acabam desenvolvendo as mesmas técnicas. A Lei 13.123 de 2015 apresenta claramente essa noção de que os conhecimentos tradicionais são coletivos, uma vez que assim dispõe no $\S 1^{\circ}$ do artigo 10 : “ $\S 1^{\circ}$ Para os fins desta Lei, qualquer conhecimento tradicional associado ao patrimônio genético será considerado de natureza coletiva, ainda que apenas um indivíduo de população indígena ou de comunidade tradicional o detenha." (BRASIL, 2015) Assim, é evidente que os conhecimentos tradicionais se mostram contrários ao conceito de propriedade privada individual, uma vez que possuem natureza coletiva.

Em que pese essa contrariedade entre conhecimentos tradicionais associados e a propriedade privada, atualmente, aplica-se, no âmbito internacional, o Acordo Trips, o qual permite a concessão de patentes em relação aos conhecimentos tradicionais associados à biodiversidade. Trata-se, portanto, de um acordo que possui natureza eminentemente comercial (VIEIRA, 2012, p. 64-68) e que visa propiciar o livre comércio no mundo globalizado. 


\section{A CONSTANTE VIOLAÇÃO DOS CONHECIMENTOS TRADICIONAIS ASSOCIADOS À BIODIVERSIDADE E O NOVO CONSTITUCIONALISMO LATINO- AMERICANO COMO CAMINHO A SER TRILHADO PARA A SUA EFETIVA PROTEÇÃO}

Dentro da ótica que prevalece no âmbito do Acordo Trips e tendo em vista o interesse econômico que, sob a ótica mercadológica, circunda os conhecimentos tradicionais, mormente a questão de fármacos, referido Acordo estabeleceu que pode ser concedida patente a qualquer invenção de produto ou processo em todos os campos da tecnologia, desde que seja nova, envolva uma atividade inventiva e seja suscetível de aplicação industrial. (ORGANIZAÇÃO MUNDIAL DO COMÉRCIO) Na sequência, apresenta casos nos quais os países podem não conceder patentes. Exceções essas que não protegem o meio ambiente ecologicamente equilibrado e a cultura, ao revés legitimam a biopirataria. (ORGANIZAÇÃO MUNDIAL DO COMÉRCIO) $)^{\dagger}$

Dessa forma, tem-se que os conhecimentos tradicionais associados à biodiversidade, quando aplicado o Acordo Trips, podem ser objeto de patente, sendo considerados direitos privados individuais, ou seja, propriedade exclusiva daquele que promoveu o patenteamento. Ou seja, um terceiro estranho à comunidade possuirá por um lapso temporal - mínimo vinte anos - o monopólio de exploração daquele "bem", sendo que a própria comunidade tradicional detentora do conhecimento dependerá, para utilização de referido conhecimento, da anuência daquele que angariou a patente e tornou-se seu proprietário. Em outras palavras,

Os direitos de propriedade intelectual - e a patente, em especial - conferem a seu titular o direito de exploração exclusiva de um determinado produto ou processo, por um determinado período de tempo, após o qual o objeto da patente cai em domínio público. Por intermédio do sistema de patentes, produtos e processos desenvolvidos a partir de recursos coletados nos países biodiversos, e mediante a utilização de conhecimentos gerados por comunidades locais, caem no domínio privado e exclusivo dos detentores dos direitos de propriedade intelectual, que são, em geral, empresas multinacionais da área biotecnológica. (SANTILLI, 2006, s.p)

É latente, portanto, que o Acordo Trips não atende aos interesses das comunidades tradicionais e, tampouco, protegem os conhecimentos tradicionais associados à biodiversidade. Isso porque ao possibilitar a concessão de patentes em relação a tais conhecimentos atenta aos interesses dos denominados bioprospectores, atrelando-se à ótica mercadológica neoliberal. Dessa maneira, concede propriedade privada individual a determinadas pessoas de conhecimentos que são, por sua natureza, coletivos. Não bastasse

\footnotetext{
† Em relação ao conceito de biopirataria, é importante ter presente que não existe na doutrina um conceito jurídico uníssona e tampouco uma definição legal. Assim, para fins do presente estudo, adota-se o entendimento de José Roque Junges (2010, p. 56), segundo o qual "A biopirataria significa a apropriação de recursos biogenéticos e/ou conhecimentos de comunidades tradicionais por indivíduos ou instituições que procuram o controle exclusivo ou o monopólio sobre estes recursos e conhecimentos, sem a autorização estatal ou das comunidades detentoras destes conhecimentos e sem a repartição justa e equitativa dos benefícios oriundos desses acessos e apropriações.”
} 
isso, as patentes conferem um valor de uso/comercial aos conhecimentos e recursos da biodiversidade, quando para as populações tradicionais, estes possuem um valor simbólico e espiritual, transcendendo qualquer representação econômica.

Sendo assim, tem-se que o Acordo Trips não se revela propício à proteção dos conhecimentos tradicionais associados, uma vez que permite a apropriação exclusiva deste por meio de terceiros estranhos às comunidades, indo, assim, de encontro à própria natureza desses direitos que são, por si só, coletivos. (VIEIRA, 2012, p. 155) Além disso, tal acordo propicia a inserção dos conhecimentos tradicionais no âmbito da ótica mercadológica, o que também não se coaduna com a origem e a finalidade dos conhecimentos em voga, visto que tais não detêm valor de mercado, mas sim, um valor espiritual, que não se revela compatível com a sua taxação em moeda ou qualquer outro bem materialmente apreciável.

Essa situação se opera, posto que com a incidência do Acordo TRIPS passa a imperar a ótica mercadológica internacional em detrimento da ótica local das comunidades tradicionais, ou seja, a busca pelo lucro e pela concorrência prepondera em relação ao direito à cultura e ao meio ambiente ecologicamente equilibrado. Nesse aspecto, não se leva em consideração que as sociedades avançam em diferentes velocidades.(OST, 1999, p. 38) Com essa medida, imputa-se um tempo único ao direito, qual seja: o tempo ditado por aqueles que detém o poder.

Em que pese a aplicação fática do Acordo Trips, é importante ter presente que ao seu lado, existe, ainda, a chamada Convenção sobre Diversidade Biológica (CDB) aprovada em 1992. Referida Convenção em questão objetiva a conservação da biodiversidade biológica, a utilização sustentável de seus componentes e a repartição justa e equitativa dos benefícios advindos da utilização dos recursos genéticos.(ORGANIZAÇÃO DAS NAÇÕES UNIDAS, 1992) Evidente, pois que diferentemente do Acordo Trips, a CDB foi criada atentando mormente aos interesses dos países do Sul, buscando, proteger, pois, os conhecimentos tradicionais e, por conseguinte, o meio ambiente ecologicamente equilibrado e a cultura.

A CDB tratou, portanto, da questão da biotecnologia, determinando que para se ter acesso aos conhecimentos tradicionais associados à biodiversidade é necessário o cumprimento cumulativo de dois requisitos, quais sejam: consentimento prévio informado, também denominado de consentimento prévio fundamentado, bem como repartição justa e equitativa dos benefícios. A partir desses dois princípios basilares da CDB, é possível verificar uma dupla implicação:

Por um lado, cabe aos países - membros estabeleceram, por meio de legislação interna, normas disciplinando o acesso e a repartição de benefícios entre países 


\section{A CONSTANTE VIOLACÃO DOS CONHECIMENTOS TRADICIONAIS ASSOCIADOS À BIODIVERSIDADE E O NOVO CONSTITUCIONALISMO LATINO- AMERICANO COMO CAMINHO A SER TRILHADO PARA A SUA EFETIVA PROTEÇÃO}

provedores e destinatários/utilizadores desses recursos; por outro lado, o respeito ao artigo 8 (j) implica o consentimento prévio fundamentado dos povos indígenas, quilombolas e populações tradicionais, detentores de conhecimentos tradicionais, e na repartição dos benefícios derivados de sua utilização com seus detentores. (SANTILLI, 2004)

Dessa forma, antes de ter acesso ao patrimônio natural e cultural, os interessados deverão, segundo o referido instrumento normativo, consultar o país de origem (SANTOS, 2005). Esse, na sequência, intermediará a consulta à população tradicional, que maneja o recurso. Frise-se que a CDB não apresenta de forma detalhada e pormenorizada a maneira e o procedimento que deve ser observado para que se obtenha referido consentimento. A questão do consentimento prévio informado mostra-se como sendo importante, posto que confere aos países do Sul poder de negociação quando se trata de acesso aos conhecimentos tradicionais, podendo-se exigir da outra parte uma contrapartida. No mesmo sentido, imperiosa se faz a manifestação das comunidades tradicionais, uma vez que isso implica na participação destas no processo que possibilita o acesso aos seus conhecimentos, o que, consequentemente, é uma garantia de proteção à sua cultura.(VIEIRA, 2012, p. 45)

A CDB é, pois, um mecanismo que reconhece a importância do meio ambiente ecologicamente equilibrado e da cultura e que busca protegê-los. O que se opera por meio da inter-relação de fatores antropogênicos e naturais, obejetivando uma ponte entre as facetas naturais e sociais do problema. (INOQUE, 2007). Sendo assim, tem-se que

\footnotetext{
[...] a CDB estabelece um novo regime internacional de acesso aos recursos genéticos. Ela reconhece um princípio antigo de que os Estados têm direitos soberanos sobre seus recursos naturais e, como tal, pode determinar as modalidades de acesso. A Convenção também determina que os benefícios da utilização desses recursos sejam repartidos de forma justa e equitativa, o acesso, quando concedido, seja regido pelas condições acordadas por mútuo acordo e pelo consentimento prévio autorizado. (MONT'ALVERNE, 2012, p. 128)
}

Apesar da latente importância da CDB em razão de seu conteúdo e dos bens que visa proteger, a mesma não estabelece obrigações, mas princípios a serem observados pelos signatários. (INOQUE, 2007) Assim, embora a CDB seja formalmente um tratado de direito internacional e possua uma estrutura institucional com alguns órgãos atrelados ao controle da sua efetividade nos países membros, a mesma possui conteúdo de soft law, ou seja, trata-se de uma Convenção que não detém caráter coercitivo e, tampouco, possibilidade de aplicação obrigatória aos Estados. .(VIEIRA, 2012, p. 50-57).

Da análise do Acordo TRIPS e da CDB verifica-se que se tratam de mecanismos que versam sobre os conhecimentos tradicionais associados e que estão vigendo concomitantemente, mas que se pautam em óticas totalmente diversas. O Acordo TRIPS 
emergiu exatamente pautado na ótica dos países do Norte, tendo o recurso natural como uma fórmula química do extrato retirado da natureza a nível molecular, que pode ser apropriada, a fim de se aferir lucros. Já a CDB objetiva conceder uma tutela mais eficaz aos conhecimentos tradicionais, uma vez que verifica que as comunidades tradicionais veem a natureza tendo por base os seus valores de uso, simbólicos e culturais, afastando-se da lógica estrita, que permeia a ciência moderna ocidental. (VIEIRA, 2012, p. 152-152).

Assim, em que pese a $\mathrm{CDB}$ tenha o condão de proteção dos conhecimentos tradicionais, na prática se aplica o Acordo TRIPS. Isso se dá a uma porque este Acordo tutela os interesses dos países do Norte, que impõe o seus anseios em relação aos países do Sul e a duas, porque se trata da normativa internacional que possui sanção pelo seu descumprimento. Sendo assim, evidente, pelo que foi explanado acima que o Acordo TRIPS não se presta para a proteção dos conhecimentos tradicionais e sendo este o instrumento, de fato, aplicado, os conhecimentos tradicionais vêm sofrendo constantes violações.

Necessário, portanto, pensar um caminho para que estes conhecimentos sejam, efetivamente, protegidos. Para tanto, na próxima seção se propõe a adoção do novo constitucionalismo latino-americano como sendo uma forma de efetiva proteção desses conhecimentos e dos direitos fundamentais que restam imbricados quando se trata desta temática.

\section{O NOVO CONSTITUCIONALISMO LATINO-AMERICANO COMO CAMINHO A SER TRILHADO PELOS PAÍSES DO SUL PARA PROTEÇÃO DOS CONHECIMENTOS TRADICIONAIS ASSOCIADOS À BIODIVERSIDADE}

Evidente, pois, que existem dois mecanismos a nível internacional que tratam sobre os conhecimentos tradicionais associados à biodiversidade. A CDB que melhor resguarda os interesses dos países do Sul e o conhecimentos tradicionais associados e o Acordo Trips, que permite a concessão de patentes em relação a esses conhecimentos. Tendo em vista que se tratam de mecanismos que não convergem entre si, no âmbito concreto aplica-se o Acordo Trips, conforme já delineado no capítulo anterior. Este, contudo, não atenta à efetiva proteção dos conhecimentos tradicionais, ao revés, sua ótica é completamente contrária a estes. Assim, o que se vislumbra é a completa inobservância da proteção desses conhecimentos, razão pela qual necessário pensar em um caminho para que os mesmos não sejam completamente aniquilados. 


\title{
A CONSTANTE VIOLAÇÃO DOS CONHECIMENTOS TRADICIONAIS ASSOCIADOS À BIODIVERSIDADE E O NOVO CONSTITUCIONALISMO LATINO- AMERICANO COMO CAMINHO A SER TRILHADO PARA A SUA EFETIVA PROTEÇÃO
}

Nesse contexto, revela-se necessário analisar a possibilidade de incutir, em âmbito brasileiro, o novo constitucionalismo latino-americano como sendo uma possibilidade de proteção, efetiva dos conhecimentos tradicionais associados. Inicialmente, nesse ponto, é importante ter presente que a Constituição de um país revela-se como sendo o elemento de validade de todo o ordenamento jurídico vigente. No Constitucionalismo moderno,

\begin{abstract}
não há mais constituições monolíticas, homogêneas, mas sínteses de conteúdos concorrentes dentro do quadro de um compromisso deliberadamente pluralista. A constituição é vista como um projeto que se expande para todas as relações sociais. O conflito é incorporado aos textos constitucionais, que não parecem representar apenas as concepções da classe dominante, pelo contrário, tornam-se um espaço onde ocorre a disputa político-jurídica.(BERCOVICI, 2011, p. 571)
\end{abstract}

Assim, as Constituições advindas a partir do século XX, incorporaram, no seu âmago, a questão pluralista, verificando que não existe apenas a visão dominante, que até então era imposta e aceita. Dentro desse aspecto, considerando que o Brasil localiza-se na América Latina e se insere em seu contexto, cabe apreciar como o constitucionalismo Latinoamericano já adotado por outras Constituições latinas pode auxiliar na proteção dos conhecimentos tradicionais associados à biodiversidade. Referida análise é relevante posto que as Constituições que seguem esse viés adotam "[...] textos constitucionais mais participativos, comprometidos com o processo de descolonização e proteção das populações locais, com forte cunho social e pluralista" (GREGORI; NASCIMENTO, 2014, p. 287) e podem, assim, vir a servir de inspiração para que, dentro da sua realidade, o Brasil possa também vir a adotar alguns dos mecanismos já incorporados a outras Constituições, mormente aqueles que legitimam a direta participação popular nas tomadas de decisão e a integração da minoria ao cenário nacional e internacional, como grupo que possui legitimidade e voz ativa.

Esse novo constitucionalismo surgiu como uma evolução do antigo Constitucionalismo Latino-americano e caracteriza-se pelas transformações que algumas Constituições Latino-americanas sofreram como influência de reivindicações sociais daqueles que dentro da sociedade possuem o denominado comportamento desviante, sendo, por isso, excluídos historicamente do processo decisório dos países respectivos. O Novo Constitucionalismo Latinoamericano surgiu, pois, de três revoltas que ocorrem em momentos e países diversos, porém com um aspecto comum: demonstram a ruptura do social, a insatisfação daqueles que até então haviam se deixado dominar, dentre os quais se encontram povos indígenas, que representam uma parcela da comunidade tradicional. Frise-se que 
embora haja uma afinidade em alguns pontos, em virtude de caracterizarem o mesmo movimento, as Constituições de cada país observaram os respectivos marcos históricoculturais. Assim, o Novo Constitucionalismo Latino-americano emergiu do Caracaço, ocorrido na Venezuela em 1989, da Guerra do Gás, que eclodiu na Bolívia em 2003 e dos protestos que se operaram no Equador em 2005.(RIBAS, s.d.)

Esses textos, além de serem os que deram origem ao Novo Constitucionalismo Latinoamericano, também, caracterizam-se por serem os mais participativos, comprometidos com o processo de descolonização e com a proteção das comunidades tradicionais. (GREGORI; NASCIMENTO, 2014, p. 287) Com base nisso, cabe analisar as referidas Constituições, com o intuito de vislumbrar o que pode ser carreado para o âmbito brasileiro.

Impera nessas Constituições a plurinacionalidade, uma vez que o Estado deve congregar em seu seio diferentes conceitos de nações. Substitui-se a uniformidade até então vigente pelo reconhecimento da convivência em um mesmo espaço geográfico e político de diversidades, que representam a denominada interculturalidade. Tem-se, assim, que

\begin{abstract}
A grande revolução do Estado Plurinacional é o fato de que este Estado constitucional, democrático participativo e dialógico pode finalmente romper com as bases teóricas e sociais do Estado nacional constitucional e democrático representativo (pouco democrático e nada representativo dos grupos não uniformizados), uniformizador de valores e logo radicalmente excludente.

O Estado plurinacional reconhece a democracia participativa como base da democracia representativa e garante a existência de formas de constituição da família e da economia segundo os valores tradicionais dos diversos grupos sociais (étnicos e culturais) existentes. (MAGALHÃES, 2008, p. 208)
\end{abstract}

A título exemplificativo, tem-se $\mathrm{o}$ artigo $1^{\circ}$ da Constituição boliviana, que deixa cristalina a adoção da plurinacionalidade, reconhecendo a interculturalidade, nos seguintes termos:

\begin{abstract}
Art. 1. Bolivia se constituye en un Estado Unitario Social de Derecho Plurinacional Comunitario, libre, independiente, soberano, democrático, intercultural, descentralizado y con autonomías. Bolivia se funda en la pluralidad y el pluralismo político, económico, jurídico, cultural y lingüístico, dentro del proceso integrador del país. (BOLÍVIA, 2003)
\end{abstract}

Ao lado desse reconhecimento explícito na Constituição da Bolívia, existem em outros artigos, detalhamentos de como este pluralismo será observado. Tal se opera por meio do reconhecimento da existência de comunidades indígenas, da necessidade de sua participação no processo de tomada de decisões e de seus idiomas, como sendo línguas oficiais do Estado.

\footnotetext{
* Tradução livre: Art. $1^{\circ}$ A Bolívia se constitui em um Estado Unitário Social de Direito Plurinacional Comunitário, livre, independente, soberano, democrático, intercultural, descentralizado e com autonomia. Bolívia se funda na pluralidade e no pluralismo político, econômico, jurídico, cultural e linguístico, dentro do processo integrador do país.
}

CONPEDI LAW REVIEW | QUITO - EQUADOR | v. 4 | n. 2 | p. 21 - 36 | JUL - DEZ | 2018 
A CONSTANTE VIOLAÇÃO DOS CONHECIMENTOS TRADICIONAIS ASSOCIADOS À BIODIVERSIDADE E O NOVO CONSTITUCIONALISMO LATINOAMERICANO COMO CAMINHO A SER TRILHADO PARA A SUA EFETIVA PROTEÇÃO

No mesmo trilho, encontra-se a Constituição Equatoriana que, também, no seu $1^{\circ}$ artigo reconhece a plurinacionalidade e a interculturalidade. Outra contribuição de tal Constituição é que esta reconhece a importância da natureza conjugando-a com a necessidade da diversidade cultural para a sua manutenção. Ao lado disso, assim como, igualmente, ocorre no âmbito da Constituição da Bolívia, a Constituição equatoriana reconhece a necessidade de bem viver da população como sendo um desiderato estatal. (ECUADOR, 2008)

A Constituição Venezuelana, da mesma forma, recebeu forte influência das comunidades tradicionais, reconhecendo em seu âmbito a importância dessas comunidades para o desenvolvimento sustentável do país. Assim, conferiu um capítulo de seu corpo para tratar apenas do assunto referente aos indígenas, uma parcela da comunidade tradicional. (VENEZUELA)

O que se vislumbra, pois, é que ao se buscar um novo constitucionalismo, deve haver a participação popular e a busca da integração de todos, ou seja, deve-se objetivar alcançar o Sumak kamaña ou o Sumak kawsay, conforme dizeres da Constituição Boliviana e Equatoriana. Em outras palavras,

El "buen vivir" apunta a una ética de lo suficiente para toda la comunidad, y no solamente para el individuo. El "buen vivir" supone una visión holística e integradora del ser humano, inmerso en la gran comunidad terrenal, que incluye además de al ser humano, al aire, el agua, los suelos, las montañas, los árboles y los animales; es estar en profunda comunión con la Pachamama (Tierra), con las energías del Universo, y con Dios. (BOOF, s.d., p. 1) ${ }^{\S}$

O conceito de bem viver estampado nas referidas Constituições coaduna-se, pois, com a relação indissociável que existe entre os direitos fundamentais ao meio ambiente ecologicamente equilibrado e à cultura quando se está diante dos conhecimentos tradicionais associados à biodiversidade. Isso porque demonstra a necessidade da manutenção do meio ambiente para a preservação da cultura e vice-versa.

Além de referida visão, as Constituições estudadas trazem, em seu cerne, mecanismos que possibilitam uma efetiva e intensa participação popular. Nesse viés, tem-se a possibilidade de exercício da democracia direta por meio de Conselhos comunais, ou de Assembleias em uma comunidade, a partir de uma democracia comunitária, ou ainda há a previsão de mandatos revocatórios, de consultas públicas e prévias vinculativas à população. Ou seja, as Constituições advindas do Novo Constitucionalismo Latino-americano não apenas

\footnotetext{
$\S$ Tradução livre: O "viver bem" demonstra uma ética do suficiente para toda a comunidade, e não apenas para o indivíduo. O "viver bem" supõe uma visão holística e integradora do ser humana, imerso na grande comunidade terrena, que inclui além do ser humano, o ar, a água, o solo, as montanhas, as árvores e os animais; é estar em profunda comunhão com o meio ambiente (terra), com as energias do Universo, e com Deus.
}

CONPEDI LAW REVIEW | QUITO - EQUADOR | v. 4 | n. 2 | p. 21 - 36 | JUL - DEZ | 2018 
reconhecem direitos, tutelando-os, mas, além disso, apresentam meios para a efetivação dos bens que visam proteger.

Dessa forma, verifica-se que a Constituição Brasileira necessitaria se refundar nessas novas bases, a fim de permitir que imperasse a soberania popular, promovendo a integração daqueles que detêm o comportamento desviante. Essa participação da população, no geral, legitimaria, de uma vez por todas, a participação das comunidades tradicionais no processo de tomadas de decisões que envolvem os conhecimentos tradicionais associados, passando-se a proteger, efetivamente, o meio ambiente ecologicamente equilibrado e a cultura.

Ao analisar a Constituição Brasileira atual, o que se vislumbra é que esta trata da proteção ao meio ambiente, à cultura, bem como confere um capítulo ao tratamento da população indígena, que configura uma parcela das comunidades tradicionais existentes em território nacional. Porém, a questão da plurinacionalidade e do interculturalismo não permeiam todo o texto constitucional, como ocorre nas Novas Constituições Latinoamericanas. Ademais, não existem mecanismos efetivos que garantam a ingerência popular no processo de tomadas de decisões, tanto é assim, que as normas que versam sobre temas intrínsecos às comunidades tradicionais acabam por não ouvir estas comunidades. Isso ficou claro por meio do processo legislativo que aprovou o atual Marco da Biodiversidade Brasileira em 2015.

Assim, necessária uma modificação do constitucionalismo nacional, a fim de que este, dentro de seu contexto histórico-cultural, altere veementemente os ditames em que a Constituição foi erigida, garantindo-se a legitima e direta participação daqueles que até então foram marginalizados. Dentre outros, deve-se, pois, assegurar a participação das comunidades tradicionais no processo de tomada de decisões e a participação destas no controle e na fiscalização da implementação de normas e políticas públicas.

Em que pese a alteração do ditame constitucional seja importante, tal não é suficiente, posto que como visto na seção anterior, a temática é tratada por meio de legislação internacional. Assim, imperiosa se faz, igualmente, uma modificação a nível internacional, alterando-se, nesse ponto, as disposições acerca da propriedade intelectual. Para tanto, seria necessária uma reformulação das normas que versam sobre a possibilidade de concessão de patentes no que tange aos conhecimentos tradicionais.

Em relação a esta alteração, deve-se ter presente que se trata de um processo árduo e complexo, uma vez que será necessário, mais uma vez, tentar conjugar os interesses dos países do Sul e dos países do Norte. Sendo assim, tem-se que o melhor caminho seria a 
A CONSTANTE VIOLAÇÃO DOS CONHECIMENTOS TRADICIONAIS ASSOCIADOS À BIODIVERSIDADE E O NOVO CONSTITUCIONALISMO LATINOAMERICANO COMO CAMINHO A SER TRILHADO PARA A SUA EFETIVA PROTEÇÃO

adoção do novo Constitucionalismo Latino-Americano pelos países do Sul e, a partir desse fortalecimento das bases nacionais, então sim, se partisse para uma negociação em âmbito internacional. Isso porque a Constituição é a norma suprema, não podendo tratados internacionais contrariarem a esta, sob pena de não possuírem validade em âmbito interno, em virtude da patente inconstitucionalidade. Nesse viés, a existência de Constituições pautadas na proteção à cultura das populações tradicionais, seria um forte argumento para a adequação das normas internacionais sobre o tema.

Evidente, pois, que a adoção pelo Brasil, bem como por outros países do Sul do Novo Constitucionalismo Latino-Americano é o início de um caminho a ser trilhado para que se possa, efetivamente, proteger os conhecimentos tradicionais associados à biodiversidade. Após esse fortalecimento no âmbito interno, os países do Sul deverão propor uma alteração da legislação internacional, para que esta passe a ser compatível com o seu texto constitucional, que protegerá os interesses das comunidades tradicionais, lhes concedendo voz e vez, e resguardando os conhecimentos tradicionais.

\section{CONSIDERAÇÕES FINAIS}

Os conhecimentos tradicionais associados à biodiversidade são pauta do cenário internacional há décadas. Nesse contexto, emergiram dois Tratados que versam e regulamentam a temática. De um lado, encontra-se a CDB, que se busca proteger a biodiversidade, tendo dois princípios fundamentais: consentimento prévio e fundamentado e repartição justa e equitativa dos benefícios. Assim, essa Convenção atenta mais aos interesses dos países do Sul. Do outro lado, tem-se o Acordo Trips, que atende aos interesses dos países do Norte, posto em que permite o patentamento dos conhecimentos tradicionais associados. Evidente, pois, que se tratam de mecanismos que vigem concomitantemente, mas que possuem interesses opostos.

Diante disso, no plano concreto apenas um deles pode ser aplicado. Sendo assim, bem como tendo em vista ser o único que possui sanção e os interesses a que atende, impera, na prática, a incidência do Acordo Trips. Ocorre que este desvirtua a própria essência dos conhecimentos tradicionais, uma vez que trata direitos coletivos, sob a ótica individual. O que se verifica, portanto, é que o Acordo Trips não se presta a proteger o meio ambiente ecologicamente equilibrado e a cultura, ao revés, legitima a biopirataria. 
Assim, considerando que os instrumentos vigentes não se revelavam aptos a proteger $\mathrm{o}$ fim a que se prestam, passou-se a cogitar a possibilidade de adoção pelo Brasil e demais países do Sul dos ditames insculpidos no Novo Constitucionalismo Latino-Americano para solucionar o impasse e proteger os conhecimentos tradicionais. Nesse viés, cumpre referir que o novo constitucionalismo Latino-Americano já foi adotado na Venezuela, no Equador e na Bolívia. Em referidos países, restou latente a questão da plurinacionalidade, do interculturalismo e da necessidade da participação popular na tomada de decisões.

Tem-se, pois, que estes ditames fortalecem a participação das comunidades tradicionais na tomada de decisões, bem como resguardam os seus conhecimentos de forma mais efetiva do que as disposições existentes em nível brasileiro. Dessa forma, bem como tendo em vista a importância da Constituição na seara jurídica interna de um país, entende-se que o caminho para proteção dos conhecimentos tradicionais inicia-se pela adoção dessa nova roupagem constitucional pelos países do Sul.

Contudo, isso, por si só, não é suficiente. Feitas as alterações constitucionais, que permitam um maior resguardo às comunidades tradicionais, caberá aos Países do Sul unidos propor a nível internacional uma negociação, que vise afastar a possibilidade de patenteamento dos conhecimentos tradicionais associados, afastando-se, pois, a aplicação do Acordo Trips, nesse ponto.

Resta evidente, pois, que a adoção do novo constitucionalismo latino-americano é o início de um caminho a ser trilhado para que, de fato, seja protegidos os conhecimentos tradicionais associados. Início de uma caminhada que se revelará árdua, complexa e, possivelmente, se alastrará por anos, posto que busca romper com o império dos países do Norte sobre os países do Sul.

\section{REFERÊNCIAS}

BERCOVICI, Gilberto. Política econômica e direito econômico. In: Pensar. v. 16.n. 2. jul./dez. 2011. Disponível em: < http://ojs.unifor.br/index.php/rpen/article/viewFile/2163/1764 >. Acesso em: 15 jul. 2015.

BOLÍVIA. Constitución Política del Estado Plurinacional de Bolivia. Disponível em <http://bolivia.infoleyes.com/shownorm.php?id=469>. Acesso em: 30 mai. 2018. 


\section{A CONSTANTE VIOLAÇÃO DOS CONHECIMENTOS TRADICIONAIS ASSOCIADOS À BIODIVERSIDADE E O NOVO CONSTITUCIONALISMO LATINO- AMERICANO COMO CAMINHO A SER TRILHADO PARA A SUA EFETIVA PROTEÇÃO}

BOFF, Leonardo. ¿Vivir mejor o "el buen vivir"?. Disponível em:

<http://www.otrodesarrollo. com/buenvivir/buenvivir_leonardoboff.pdf>. Acesso em: 20 ago. 2015 .

BRASIL. DECRETO 6.040, de 07 de fevereiro de 2007. Disponível em: < http://www.planalto.gov.br/ccivil_03/_ato2007-2010/2007/decreto/d6040.htm>. Acesso em: 1 jun. 2018.

BRASIL. LEI 13.123, de 20 de maio de 2015. Disponível em: <http://www.planalto.gov.br/ccivil_03/_Ato2015-2018/2015/Lei/L13123.htm >. Acesso em: 01 jun. 2018.

DIEGUES, Antônio Carlos; ARRUDA, Rinaldo S. V. (Orgs.). Saberes tradicionais e biodiversidade no Brasil. Brasília: Ministério do Meio Ambiente; São Paulo: USP, 2001.

ECUADOR. Constitución Política del Ecuador. Disponível em:

<http://biblioteca.espe.edu.ec/upload/2008.pdf>. Acesso em: 30 mai. 2018.

GREGORI, Isabel Christine de; NASCIMENTO, Valéria Ribas do. Constitucionalismo Latinoamericano e biodiversidade: limites e perspectivas de um sistema "sui generis" de proteção aos direitos fundamentais das comunidades tradicionais. In: Revista da Faculdade de Direito: Universidade Federal de Minas Gerais. n. 65. jul./dez. 2014. Belo Horizonte.

INOUE, Cristina Yume Aoki. Regime global da biodiversidade: o caso Mamirauá. Brasília: Universidade de Brasília, 2007.

JUNGES, José Roque. (Bio) Ética Ambiental. São Leopoldo: Ed. Unisinos, 2010.

MAGALHÃES, José Luiz Quadro de. Plurinacionalidade e cosmopolitismo: A diversidade cultural das cidades e diversidade comportamental nas Metrópoles. In: Revista Faculdade Direito: Universidade Federal de Minas Gerais. n. 53. jul./dez. 2008. Belo Horizonte.

Disponível em: <

http://www.direito.ufmg.br/revista/index.php/revista/article/viewFile/83/79>. Acesso em 30 mai. 2018.

MONT'ALVERNE, Tarin Cristino Frota. O acesso aos recursos genéticos e o protocolo de Nagoya. In: MARINHO, Maria Edevalcy P.; CALSING, Renata de Assis. Propriedade Intelectual e Meio Ambiente. Brasília: Dreams Gráfica e Editora, 2012.

ORGANIZAÇÃO DAS NAÇÕES UNIDAS - ONU. Convenção sobre Diversidade Biológica. Disponível em: 
रWWw.mma.gov.br/estruturas/sbf_chm_rbbio/_arquivos/cdbport_72.pdf> . Acesso em: 09 jun. 2018.

ORGANIZAÇÃO MUNDIAL DO COMÉRCIO - OMC. Acordo sobre aspectos dos direitos de propriedade intelectual relacionados ao comércio (acordo TRIPS ou acordo ADPIC). Disponível em: <http://www2.cultura.gov.br/site/wp-content/uploads/ 2008/02/ac_trips.pdf >. Acesso em: 09 jun. 2018.

OST, François. O tempo do Direito. Porto Alegre: Instituto Piaget, 1999.

RIBAS, José Vieira. Refundar o estado: O Novo Constitucionalismo Latino-Americano. Disponível em: <http://www.direito.ufg.br/up/12/o/24243799-UFRJ-NovoConstitucionalismo-Latino-Americano.pdf?1352146239 >. Acesso em: 30 mai. 2018.

SANTOS, Laymert Garcia dos. Quando o conhecimento tecnocientífico se torna predação hight-tech: recursos genéticos e conhecimentos tradicionais no Brasil. In: SANTOS, Boaventura de Sousa. Semear outras soluções: os caminhos da biodiversidade e dos conhecimentos rivais. Rio de Janeiro: Civilização Brasileira, 2005.

SANTILLI, Juliana. Socioambientalismos e novos direitos: A proteção jurídica da diversidade biológica e cultural. São Paulo: Fundação Peirópolis, 2005.

SANTILI, Juliana. Conhecimentos tradicionais associados à biodiversidade: elementos para a construção de um regime jurídico sui generis de proteção. In: VARELLA, Marcelo Dias; BARROS-PLATIAU, Ana Flávia (Org.). Diversidade Biológica e Conhecimentos Tradicionais. 2. ed. Del Rey: Belo Horizonte, 2004.

SANTILLI, Juliana. Conhecimentos tradicionais associados à biodiversidade: Elementos para a construção de um regime jurídico "sui generis" de proteção. In: Encontro Anual da Associação Nacional de Pós-Graduação e Pesquisa em Ambiente e Sociedade. Disponível em: < http://www.anppas.org.br/encontro_anual/encontro2/GT/GT08/juliana_santilli.pdf >. Acesso em: 31 mai. 2018.

VENEZUELA. Constitución de la República Bolivariana de Venezuela. Disponível em <http://www.mppeu.gob.ve/web/uploads/PDF/constitucion.pdf>. Acesso em: 30 mai. 2018.

VIEIRA, Vinícius Garcia. Direito da biodiversidade e América Latina: a questão da propriedade intelectual. Ijuí: Unijuí, 2012. 